\title{
Effect of the Heterogeneous Nucleation of the Primary $\alpha$-Al Grain Via the Al-4Nb-0.5B Master Alloy in Al-Si Alloys With High Fe Contents
}

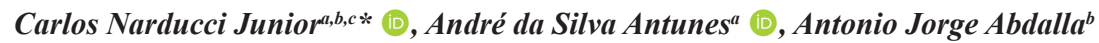 \\ aInstituto Tecnológico de Aeronáutica (ITA), São José dos Campos, SP, Brasil \\ ${ }^{b}$ Instituto de Estudos Avançados (IEAv), São José dos Campos, SP, Brasil \\ 'Instituto Federal de São Paulo (IFSP), Itaquaquecetuba, SP, Brasil
}

Received: December 01, 2020; Revised: April 26, 2021; Accepted: April 27, 2021

\begin{abstract}
Grain refinement in Al-Si alloys improves their mechanical properties. Research available in the literature shows the search for refinement efficiency through heterogeneous nucleation of the grain, involving the stoichiometric ratio between the alloy elements, the inoculant, and process parameters. In these surveys, there are divergences of information. However, this study does not aim to contradict this information but present an investigation made with the $\mathrm{Al}-4 \mathrm{Nb}-0.5 \mathrm{~B}$ master alloy, where $\mathrm{Nb}>>\mathrm{B}$, used via sticks, with variations from 0 to $1 \mathrm{Wt} . \%$ of $\mathrm{Nb}$ and $\mathrm{B}$ according to a stoichiometric calculation added to the alloys cast with $\mathrm{Al}(7,9,12) \mathrm{Wt} . \%$ of $\mathrm{Si}$ and $1 \mathrm{Wt} . \%$ of Fe. The study also enabled an investigation into the morphology behavior of the $\beta$-Fe precipitates arising from Fe-critic in the alloy. Samples cast according to the TP1-2012 mold standard. The alloy microstructure analyzed was by energy-dispersive X-ray spectroscopy. The small addition of $\mathrm{Nb}$-B can efficiently and significantly refine the size of the primary $\alpha$-Al grain and has caused changes in the morphology of Fe-rich intermetallic, which became very refined spheroidised, suggesting an improvement in the mechanical properties of the material.
\end{abstract}

Keywords: Al-Si alloys, (Nb-B) ratio, grain refinement, intermetallic precipitation, casting.

\section{Introduction}

It is highly desirable to obtain a structure of refined grains in the Al-Si alloys due to the gain in mechanical properties in terms of resistance and elasticity in the cast parts. However, due to the iron $(\mathrm{Fe})$ element's contamination during collection and processing of recycled $\mathrm{Al}$ the material's elasticity is compromised $^{1,2}$. Mahta et al. ${ }^{3}$ reports that the presence of the element $\mathrm{Fe}$ in the $\mathrm{Al}-\mathrm{Si}$ alloys, even in small amounts, promotes the formation of the intermetallic phase $\beta-\mathrm{Al} 5 \mathrm{FeSi}$ $(\beta-\mathrm{Fe})$, with morphology in the form of a plate or needle, which deteriorates the mechanical properties of the material. Taylor ${ }^{1}$ demonstrates this through the net projection section of the rich Al-Si-Fe corner of the ternary phase diagram. It has a critical iron content, where the level of iron (Fe-critical) is directly related to Alloy Si's concentration. Therefore, the higher the Si content in the alloy, the higher the permissible Fe content, i.e., in an alloy with $11 \mathrm{Wt}$. \% of Si, it can have a maximum of $0.75 \mathrm{Wt}$. $\%$ of Fe. A proposed solution to combat the Fe-critical was the mechanism of modifying the intermetallic precipitates with the addition of some elements, with Mn being the most used, due to the formation of $\alpha-\mathrm{Al}_{15}(\mathrm{FeMn})_{3} \mathrm{Si}_{2}$, i.e., replacing of $\beta-\mathrm{Fe}$ with $\alpha-\mathrm{Fe}^{3}$. However, a new problem may arise with this mechanism due to the so-called sludge formation which destroys the material's mechanical properties ${ }^{4}$. The most straightforward approach to counter the iron impurity level is to dilute the recycled aluminum using primary aluminum, but eventually, it makes the Al-Si alloys more expensive. Basak

*e-mail: cnarducci@ifsp.edu.br and $\mathrm{Babu}^{5}$ suggested the fragmentation theory as the primary mechanism for refining the $\beta$ phase, based on experimental evidence. According to this theory, the morphological change of the $\beta$-phase can be induced by appropriate heat treatment. However, it is recommended only in the low-Si high-Fe content; it is not to the recyclable Al-Si alloy. Basak and $\mathrm{Babu}^{5}$ also proposed another approach, gravitational segregation, but this is not a good productivity process. A cost-benefit analysis would be necessary to show the advantages of using these techniques economically.

From the classical theory of heterogeneous nucleation used in the phenomenon of grain refinement in Al-Si alloys, the possibility that one of the effects of this transformation could be the most homogeneous distribution of solute elements arises, in the case $\mathrm{Fe}$, in the solidification fronts. This transformation can be done during the eutectic phase of the material solidification, thus avoiding the interconnectivity of the Fe elements dispersed in the liquid metal in the shape of a needle or thick platelet. In this direction, the fast cooling rate is the relevant factor in obtaining a fine grain structure. The higher the cooling rate, the smaller the grain size, such as in high-pressure die-casting (HPDC). However, for technical or economic reasons, a good part of castings are produced in sand casting processes or casting in permanent molds by gravity, where the cooling rate is slow, causing coarse grain in the material structures. One solution found by engineering to improve grain refinement in these types of castings is to drive the heterogeneous nucleation of $\alpha$-Al grains through the 
intentional addition of inoculant elements. In this direction, Easton and St John ${ }^{6}$ confirmed that Ti is an element with an excellent growth restriction factor. Therefore inoculation with the addition of Al-Ti-B is powerful grain refiners when used in the production of stamp parts in Al. However, $\mathrm{Al}$ alloys for the stamping process generally use quantities lower than $2 \mathrm{Wt} . \%$ of Si. In Al-Si alloys for casting, studies with much higher Si levels would be necessary, with additions above $4 \%$, to ensure its reliability in the final products' quality. As reported by Nowak et al. ${ }^{7}$ the inoculant's efficiency based on Al-Ti-B is doubtful when using Si contents higher than $4 \mathrm{Wt} . \%$, proving that $\mathrm{Ti}$ together with $\mathrm{Si}$ interacts to form titanium silicates, which are ceramic compounds and end up damaging the mechanical properties of the materials. However, this is a discussion with many controversies. This phenomenon has been treated as a poisoning effect on the alloy ${ }^{7-9}$. The alternative found by engineering among the elements available in the periodic table was $\mathrm{Nb}$. The reasons for choosing $\mathrm{Nb}$ were a higher melting point - a slightly lower network parameter with lower incompatibility than $\mathrm{Ti}$, which favors the molten Al's solidification. Bolzoni et al. ${ }^{10}$ confirmed that the primary $\alpha$-Al dendrites' refinement with $\mathrm{Nb}$-based inoculant is highly effective, proving through the $\mathrm{AlB} 2, \mathrm{Al} 3 \mathrm{Nb}$ intermetallic precipitates found in the nucleation of the grains.

The studies with the inoculant $\mathrm{Nb}+\mathrm{B}$ also analyzed the distribution of the secondary phase in Al-Si alloys without and with inoculation $\left(\mathrm{NbB}_{2} / \mathrm{Al}_{3} \mathrm{Nb}\right)$. During solidification, $\mathrm{Si}$ is rejected by the growing grains until the point where the remaining liquid reaches the eutectic composition, and the eutectic phase nucleates and solidifies between the dendrite arms of the primary $\alpha$-Al grains. Therefore, the Al-Si reference alloys develop a non-uniform distribution of the secondary phase confined between the dendritic arms of the thick primary $\alpha$-Al grains, as shown in Figure 1a. After inoculation with $\mathrm{Nb}$-based substrates, the eutectic phase distribution is much more homogeneous, as shown in Figure 1b. This is a consequence of the refinement of the primary $\alpha-\mathrm{Al}$ dendritic grains, whose greater number and smaller size lead to a more uniform distribution of the secondary eutectic $\mathrm{Si}$ in the melt structure ${ }^{5,11}$. This is because the ingenious and powerful heterogeneous cores promote nucleation overgrowth at both stages of the solidification process. Therefore solidification is less dependent on heat extraction and grain growth. Nb-based substrates open up the possibility to design structural engineering components with homogeneous and enhanced performance.
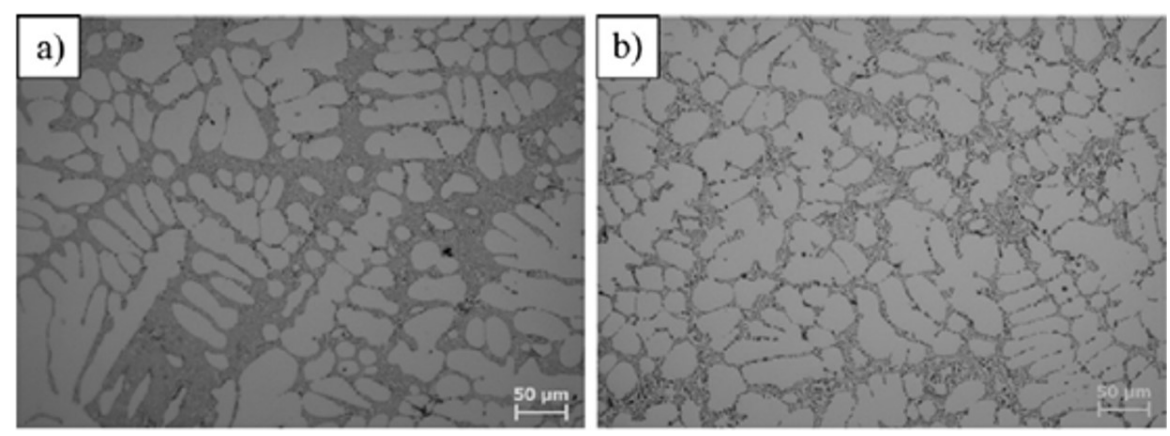

Figure 1. Details of the distribution of the secondary eutectic Si phase and b-Fe precipitates in Al-Si alloys: (a) without inoculation (reference) and (b) with inoculation $\left(\mathrm{NbB}_{2} / \mathrm{Al}_{3} \mathrm{Nb}\right)^{11}$.
However, Nb-B's application in the Al-Si alloys for grain refinement has been causing some concerns. Among them are the problems related to using $\mathrm{Nb}$ 's ratio to $\mathrm{B}(\mathrm{Nb} / \mathrm{B})$. That is $\mathrm{Nb}>\mathrm{B} ; \mathrm{Nb}=\mathrm{B}$ and $\mathrm{Nb}<\mathrm{B}$ and the form of its addition (i.e., $\mathrm{Nb}$ powder, Potassium tetrafluoroborate KBF4 flux or Al-Nb-B master alloy), they are variables that end up influencing the efficiency of grain refinement. In addition to these variables, one can also mention the manufacturing process, the processing parameters, and the nature of the raw materials used as essential factors to control efficiency in the refinement of grains ${ }^{12,13}$. To better understand this subject, made comparisons between the results of grain refinement taken from the available literature, where produced samples with parameters similar to those used in this work, as the inoculation via $\mathrm{Nb}-\mathrm{B}$ with the same conditions of $\mathrm{Nb}$ addition content, but with $\mathrm{B}$ varying according to stoichiometric calculation (variations in the $\mathrm{Nb}-\mathrm{B}$ ratio). All samples were cast using the same casting process using the standard test procedure mold TP- $1^{14}$, where the cooling rate is $\left(\sim 3.0^{\circ} \mathrm{C} / \mathrm{s}\right)$; however, the samples cast with different types of alloys. In Table 1, the results are summarized and shown, with their respective consultation sources.

\section{Experimental Procedure}

The Al alloys $(7,9,12)$ wt. \% Si - 1 wt. \% Fe were used as the base alloys to analyze the effect of $\mathrm{Nb}$ addition via Al$4 \mathrm{Nb}-0.5 \mathrm{~B}$ master alloy in the size of the $\alpha$-Al grain, eutectic phase of Al-Si, and intermetallic precipitates. The level of $\mathrm{Nb}-\mathrm{B}$ added to each alloy is shown in Table 2.

The studied alloys were cast in an open resistive over with a tilting ceramic crucible with a melting capacity of $3 \mathrm{~kg} \mathrm{Al}$. The primary $\mathrm{Al}$ (supplied by HYDRO) was heated and stabilized at $800^{\circ} \mathrm{C}$ (an immersion pyrometer controlled the temperature). The alloying elements $\mathrm{Si}$ (supplied by LIASA) were added in percentages of 7, 9, and $12 \mathrm{Wt} . \%$, one portion at a time, along with the Fe element (supplied by MEXTRAMETAL) with $1 \mathrm{Wt} \%$. After adding each element, a 1-hour hold was applied to ensure complete dissolution. After that, the bath was homogenized by mechanical (manual) stirring for $30 \mathrm{~s}$. Degasification was then used by adding hexacloroetano tablets (supplied by ALFA TREND) to the bath in a proportion of $0.1 \mathrm{Wt} . \%$, followed by manual slag removal. After the preparation of each Al-Si-Fe based alloy, progressive amounts of $\mathrm{Nb}$ were added to the bath in the form of sticks by way of the Al- $4 \mathrm{Nb}-0.5 \mathrm{~B}$ master alloy (provided by Brazilian Metallurgy and Mining Company CBMM), with additional levels ranging from 0 to $1 \%$. For each $\mathrm{Nb}$ level, homogenization was achieved by $30 \mathrm{~s}$ of manual 
Table 1. Comparative summary of studies.

\begin{tabular}{|c|c|c|c|c|c|c|c|}
\hline \multicolumn{8}{|c|}{ Research taken from the literature } \\
\hline \multirow{2}{*}{ Factors } & \multicolumn{7}{|c|}{ Bibliographic reference } \\
\hline & 15 & 10 & 7 & 16 & 17 & 18 & 12 \\
\hline $\begin{array}{c}\text { casting } \\
\text { parameters }\end{array}$ & $\begin{array}{c}\text { melted } 850^{\circ} \mathrm{C} \text {; } \\
\text { homogenise } \\
2 \mathrm{~h} \text {; electic } \\
\text { furnace; } \\
\text { stirringe } 15 \\
\text { min during } 2 \mathrm{~h} \text {. }\end{array}$ & $\begin{array}{c}\text { melted } 790^{\circ} \mathrm{C} ; \\
\text { homogenise } \\
1 \mathrm{~h} \text {; pouring } \\
\text { temperature } \\
740^{\circ} \mathrm{C} \text {; conect } \\
\text { time }(\mathrm{Nb}) 30 \\
\text { min. } \\
\end{array}$ & $\begin{array}{c}\text { melted } 800^{\circ} \mathrm{C} \text {; } \\
\text { homogenise } \\
\text { lh; pouring } \\
\text { temperature } \\
720^{\circ} \mathrm{C} .\end{array}$ & $\begin{array}{c}\text { melted } 800^{\circ} \mathrm{C} \text {; } \\
\text { homogenise } \\
1 \mathrm{~h} \text {; electric } \\
\text { furnace; } \\
\text { pouring } \\
\text { temperature } \\
740^{\circ} \mathrm{C} \text {. }\end{array}$ & $\begin{array}{l}\text { melted } 690^{\circ} \mathrm{C} \\
\text { conect time } \\
(\mathrm{Nb}) 30 \mathrm{~min} .\end{array}$ & $\begin{array}{c}\text { melted } 790^{\circ} \mathrm{C} ; \\
\text { pouring } \\
\text { temperature } \\
740^{\circ} \mathrm{C} \text {; conect } \\
\text { time }(\mathrm{Nb}) 30 \\
\text { min. }\end{array}$ & $\begin{array}{c}\text { melted } 790^{\circ} \mathrm{C} \text {; } \\
\text { stirringe } 15 \\
\text { min; pouring } \\
\text { temperature } \\
740^{\circ} \mathrm{C} \text {; conect } \\
\text { time }(\mathrm{Nb}) 30 \\
\text { min. }\end{array}$ \\
\hline \multirow{3}{*}{ Ratio (Nb/ B) } & \multirow{3}{*}{$4: 1 \mathrm{Nb}>\mathrm{B}$} & \multirow{3}{*}{$1: 1 \mathrm{NB}=\mathrm{B}$} & $2: 1 \mathrm{Nb}>\mathrm{B}$ & \multirow{3}{*}{$1: 1 \mathrm{Nb}=\mathrm{B}$} & \multirow{3}{*}{$4: 1 \mathrm{NB}>\mathrm{B}$} & \multirow{3}{*}{$1: 1 \mathrm{NB}=\mathrm{B}$} & \multirow{3}{*}{$2: 1 \mathrm{NB}>\mathrm{B}$} \\
\hline & & & $1: 1 \mathrm{Nb}=\mathrm{B}$ & & & & \\
\hline & & & $1: 2.5 \mathrm{Nb}<\mathrm{B}$ & & & & \\
\hline \multirow{2}{*}{ Addition via } & \multirow{2}{*}{ master alloy } & \multirow{2}{*}{ master alloy } & $\mathrm{Nb}$ powder & $\mathrm{Nb}$ powder & \multirow{2}{*}{ master alloy } & \multirow{2}{*}{ master alloy } & \multirow{2}{*}{ master alloy } \\
\hline & & & KBF4 flux & KBF4 flux & & & \\
\hline Alloy & LM6 & LM6 & $\begin{array}{l}\text { Commercial } \\
\text { pure Al }\end{array}$ & LM6 & AZ9 1D & LM25 & $\mathrm{Al10Si}$ \\
\hline \multirow{3}{*}{$\begin{array}{l}\text { Avarage grain } \\
\text { size }(\mu \mathrm{m})\end{array}$} & \multirow{3}{*}{340} & \multirow{3}{*}{250} & 1350 & \multirow{3}{*}{500} & \multirow{3}{*}{220} & \multirow{3}{*}{400} & \multirow{3}{*}{250} \\
\hline & & & 450 & & & & \\
\hline & & & 435 & & & & \\
\hline
\end{tabular}

Table 2. Nb-B level range added to Al-Si-Fe alloys.

\begin{tabular}{cccccccc}
\hline Combination & $I$ & $I I$ & $I I I$ & $I V$ & $V$ & $V I$ & VII \\
\hline $\boldsymbol{N} \boldsymbol{b}(\boldsymbol{W t} . \%)$ & 0 & 0.02 & 0.05 & 0.1 & 0.2 & 0.5 & 1 \\
\hline $\boldsymbol{B}$ (Wt.\%) & 0 & 0.0025 & 0.00625 & 0.0125 & 0.025 & 0.0625 & 0.125 \\
\hline
\end{tabular}

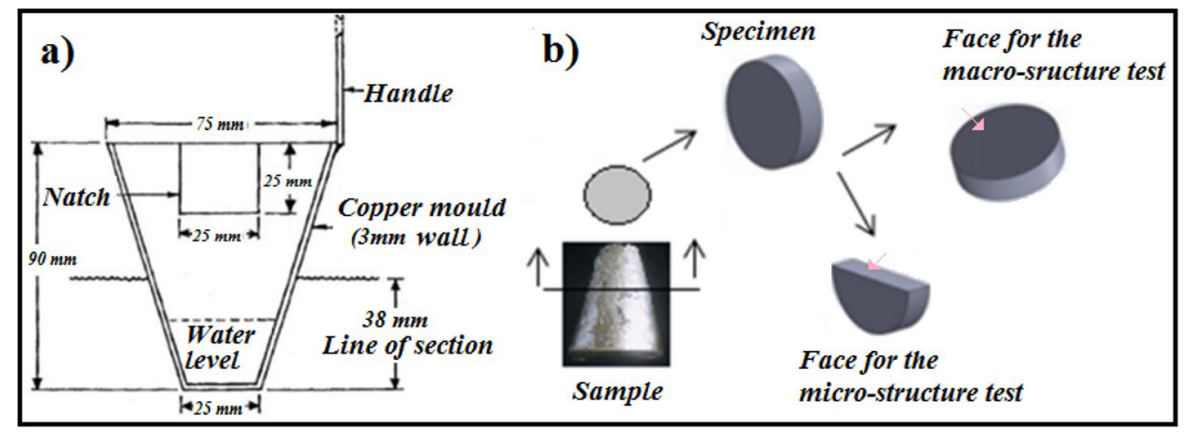

Figure 2. Illustrative sketch. a) Mould ladle. b) Cut the sample.

stirring and a new stabilization at $720^{\circ} \mathrm{C}$, followed by a second homogenization and sample collection.

Seven samples were obtained from each batch. The extraction of the samples was performed according to the procedure described by the standard mold technique, Test Procedure, TP- $1^{14}$, as follows:

The TP-1 mold ladle (Figure 2a) was placed inside a furnace for heating at $350^{\circ} \mathrm{C}$; The water flow rate of the TP-1 mold quench tank was set to $3.8 \mathrm{l} / \mathrm{min}$. This flow rate resulted in a $25 \mathrm{~mm}$ submersion from the bottom ladle; The test sample removed from the TP-1 conical mold was cut according to the standard procedure ( $38 \mathrm{~mm}$ above the base) as illustrated in Figure 2.b. The cooling rate at this position corresponds to $3.5^{\circ} \mathrm{C} / \mathrm{s}$.

Various factors affect the solidification microstructure of a given alloy, but one of the most important is the cooling rate. By keeping the cooling rate constant, we can examine the effect of heterogeneous additions on the grain size. The standard Test Procedure-1 (TP-1) mold technique maintains a regular cooling rate.
The samples were machined $30 \mathrm{~mm}$ in diameter and $15 \mathrm{~mm}$ in height. The cross-sectional surfaces were prepared with 2400 mesh sandpaper, without polishing, to analyze the grain size. After the metallurgical preparation, the samples were attacked for 15 seconds with a Poulton acid solution (60\% HCL at $37 \% ; 30 \% \mathrm{HNO}_{3}$ at $65 \% ; 5 \% \mathrm{HF}$ at $50 \%$ and $5 \% \mathrm{H}_{2} \mathrm{O}$ ), then washed in water for 20 seconds. They were whitened with $(67 \%$ $\mathrm{HNO}_{3}$ at $65 \%, 5 \% \mathrm{HF}$ at $50 \%$, and $13 \% \mathrm{H}_{2} \mathrm{O}$ ) for 15 seconds. For the analysis of microstructural constituents, the surfaces of the cross-section after being prepared with 2400 mesh sandpapers, were polished with $1 \mu \mathrm{m}$ alumina suspension and then chemically etched with the Keller reagent $(95.0 \mathrm{ml}$ of distilled water, $2.5 \mathrm{ml}$ of $\mathrm{HNO}_{3}, 1.5 \mathrm{ml}$ of $\mathrm{HCl}$ and $1.0 \mathrm{ml}$ $\mathrm{HF}$ ) to reveal their microstructural constituents. The initial macroscopic and microscopic analyses were measured in the cutting plane, with 50x and 100x magnification. The macro and microstructures were examined in an optical microscope with polarized light and filter plate and differential interference contrast (DIC) to reveal primary grains of $\alpha$-Al to show grain limits. The images were taken from random positions along 
the sample section. The measurement of the average grain size (G) was conducted by the linear intercept method according to ASTM standard ${ }^{19}$. The measurement was calculated by counting the number of grains that intercept a line of known size. The eutectic phase of Al-Si and intermetallic precipitates were analyzed by X-ray Dispersive Energy Spectroscopy (EDS). The analysis was performed on the samples with a Tescan scanning electron microscope with an EDS detector analyzer from Oxford Instruments to obtain the $\mathrm{Al}, \mathrm{Si}$, and Fe spatial spectrums. The images were taken from random positions along the samples section.

\section{Results and Discussion}

The microstructural analysis of the samples identified the substrates responsible for the different nucleation fronts in the material after adding the $\mathrm{Nb}+\mathrm{B}$ inoculant, as shown in Figure 3a, b.

These substrates are composed of the elements ( $\mathrm{Al}, \mathrm{Nb}$, and $\mathrm{B})$, which react to form niobium aluminides $\left(\mathrm{Al}_{3} \mathrm{Nb}\right)$ and niobium borides $\left(\mathrm{NbB}_{2}\right)$. A remark should be made, regarding the magnification allowed by the SEM-EDS technique used herein, due to being limited in analyses requiring higher magnifications, which suggests an investigation via TEM analysis, outside the scope of this work. However, can see further evidence of heterogeneous nucleation of $\alpha$-Al grains in the study of Bolzoni and $\mathrm{Babu}^{11}$ where it was demonstrated that the $\mathrm{Al}_{3} \mathrm{Nb}$ and $\mathrm{NbB}_{2}$-based heterogeneous nuclei have substrates that present a typical tetragonal and hexagonal plate-like morphology, respectively, as per the TEM bright image shown in Figure 4 of the $\mathrm{NbB}_{2}$ substrates. These substrates remain stable after casting the alloy. Based on this, it was possible to verify that they are formed according to Equation 1 and $2^{11}$ :

$$
\mathrm{Nb}+3 \mathrm{Al} \rightarrow \mathrm{Al}_{3} \mathrm{Nb}
$$

$$
\mathrm{Al}_{3} \mathrm{Nb}+\mathrm{AlB}_{2} \rightarrow \mathrm{NbB}_{2}+4 \mathrm{Al}
$$

These substrates promote the necessary subcooling for nucleation of the primary $\alpha-\mathrm{Al}$ grain and initiate several nucleation points at the same time during the material solidification phase limiting the size of the dendrites $\alpha-\mathrm{Al}$ grain primary ${ }^{20}$. In addition to causing grain refinement, this phenomenon also creates a mechanism that ends up modifying the morphology of $2^{\text {nd }}$ phase precipitates ${ }^{16,21}$, such as $\beta$-Fe.

As described in the experimental procedure, samples prepared were photographed, their images captured and used to calculate the average number of grains. Some examples of these images are presented below:

Figures 5, 6, and 7 show the crystallographic structure images captured from the alloy samples without and with increasing $\mathrm{NbB}, \mathrm{Al} 7 \mathrm{Si} 1 \mathrm{Fe}, \mathrm{A} 19 \mathrm{Si1Fe}$, and A112Si1Fe, respectively.
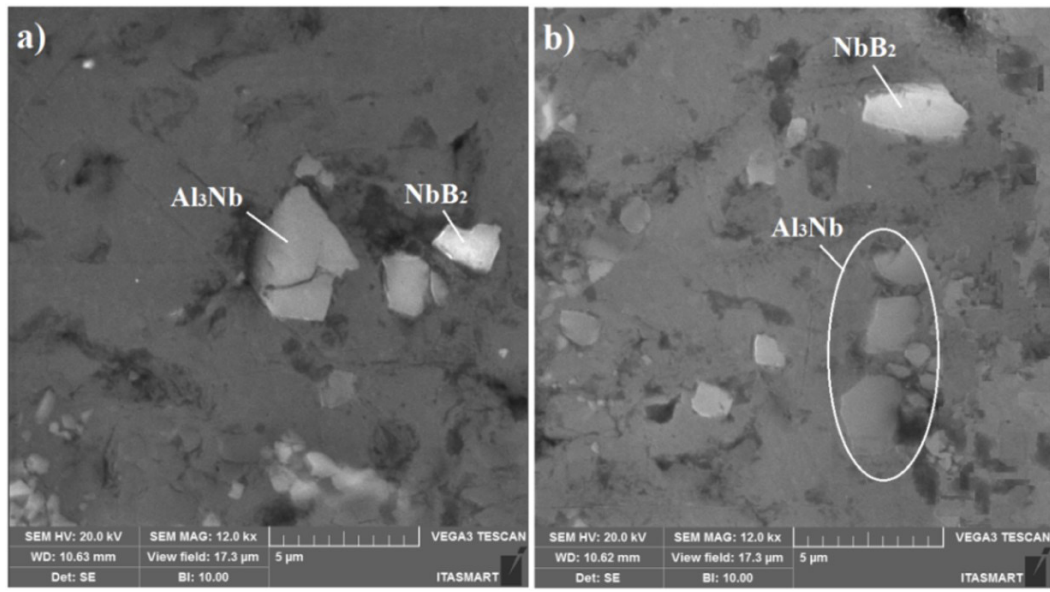

Figure 3. ( $\mathrm{a}$ and b) $\mathrm{Al}_{3} \mathrm{Nb}$ and $\mathrm{NbB}_{2}$ substrates identified in the scanning electron microscope (SEM), with a detector analyzer (SEM-EDS), present in the core of the primary $\alpha$-Al grain, found in the Al7Si1Fe alloy, with the addition of $0.5 \% \mathrm{Nb}$.
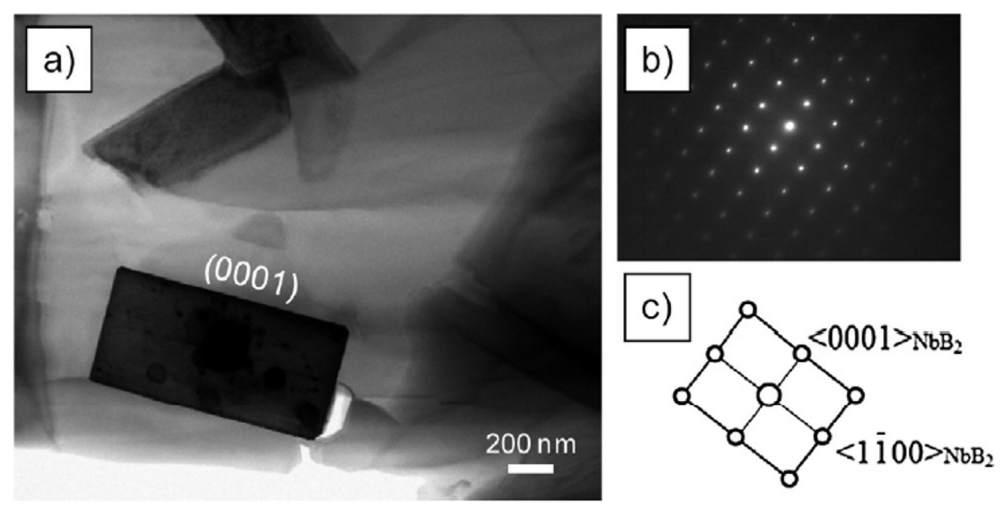

Figure 4. The representative TEM analyses result from the heterogeneous nuclei present in Al-Nb-B master alloy: (a) bright field micrograph showing the hexagonal plate-like morphology of $\mathrm{NbB}_{2}$ substrate, and (b, c) diffraction pattern of $\mathrm{NbB}_{2}$ substrates ${ }^{11}$. 
The average grain size was calculated using the manual methodology standardized according to the linear intercept method in the images. The values were registered in Table 3 and plotted in Figure 8. The differences in grain size found in the samples were compared with the Al alloys' stoichiometric combinations.

Table 3. Static values calculated for the average grain size.

\begin{tabular}{|c|c|c|c|c|c|c|}
\hline \multicolumn{7}{|c|}{ Static parameters calculated for the average grain size methodology ASTM E112 ${ }^{19}$} \\
\hline Alloy & $\% \mathrm{Nb}$ & $\% \mathrm{~B}$ & sample size & $\begin{array}{l}\text { average grain } \\
\text { size }(\mu \mathrm{m})\end{array}$ & $\begin{array}{c}\text { standard } \\
\text { deviation }\end{array}$ & $\begin{array}{c}\text { confidence limits } \\
95 \%(+/-)\end{array}$ \\
\hline \multirow{7}{*}{ Al7SI1Fe } & 0 & 0 & 80 & 1221 & 157,3 & 0,39 \\
\hline & 0,02 & 0,0025 & 20 & 268 & 18,4 & 0,26 \\
\hline & 0,05 & 0,00625 & 20 & 104 & 2,5 & 0,04 \\
\hline & 0,1 & 0,0125 & 20 & 170 & 11,5 & 0,16 \\
\hline & 0,2 & 0,025 & 20 & 160 & 8,6 & 0,12 \\
\hline & 0,5 & 0,0625 & 30 & 218 & 25,3 & 0,29 \\
\hline & 1 & 0,1255 & 20 & 155 & 12,7 & 0,18 \\
\hline \multirow{7}{*}{ Al9SI1Fe } & 0 & 0 & 80 & 787 & 68,4 & 0,34 \\
\hline & 0,02 & 0,0025 & 20 & 151 & 10,0 & 0,14 \\
\hline & 0,05 & 0,00625 & 20 & 120 & 6,4 & 0,09 \\
\hline & 0,1 & 0,0125 & 20 & 167 & 17,3 & 0,24 \\
\hline & 0,2 & 0,025 & 20 & 227 & 12,2 & 0,17 \\
\hline & 0,5 & 0,0625 & 60 & 357 & 35,2 & 0,35 \\
\hline & 1 & 0,1255 & 30 & 231 & 16,4 & 0,19 \\
\hline \multirow{7}{*}{ Al12SI1Fe } & 0 & 0 & 80 & 897 & 112,3 & 0,39 \\
\hline & 0,02 & 0,0025 & 20 & 286 & 10,5 & 0,15 \\
\hline & 0,05 & 0,00625 & 20 & 222 & 5,8 & 0,08 \\
\hline & 0,1 & 0,0125 & 20 & 232 & 19,5 & 0,27 \\
\hline & 0,2 & 0,025 & 40 & 345 & 26,2 & 0,26 \\
\hline & 0,5 & 0,0625 & 60 & 254 & 43,7 & 0,31 \\
\hline & 1 & 0,1255 & 60 & 321 & 19,5 & 0,32 \\
\hline
\end{tabular}
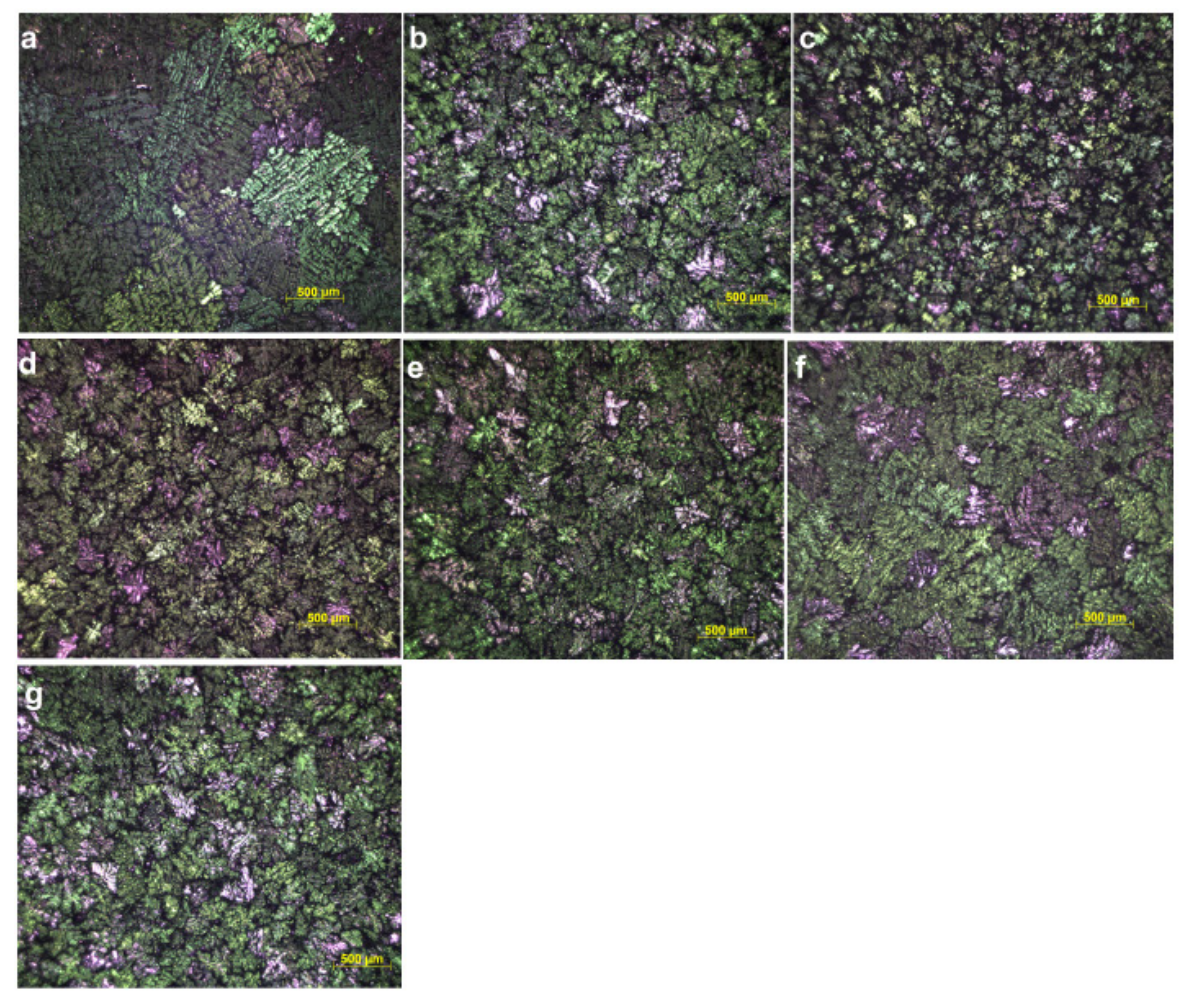

Figure 5. Al7Si1Fe" $X " N b B$ alloy, where: a) $X=0 \%$. b) $X=0.02 \%$. c) $X=0.05 \%$. d) $X=0.1 \%$. e) $X=0.2 \%$. f) $X=0.5 \%$. g) $X=1 \%$. 


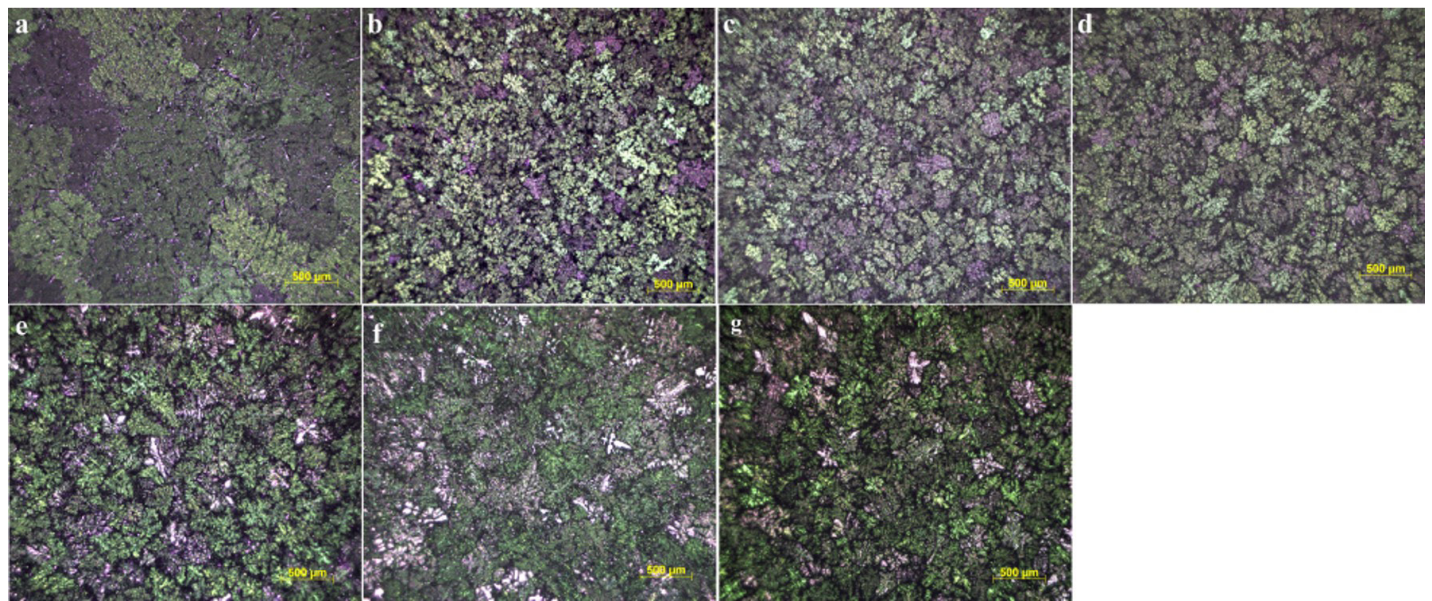

Figure 6. A19Si1Fe" $X " N b B$ alloy, where: a) $X=0 \%$. b) $X=0.02 \%$. c) $X=0.05 \%$. d) $X=0.1 \%$. e) $X=0.2 \%$. f) $X=0.5 \%$. g) $X=1 \%$.
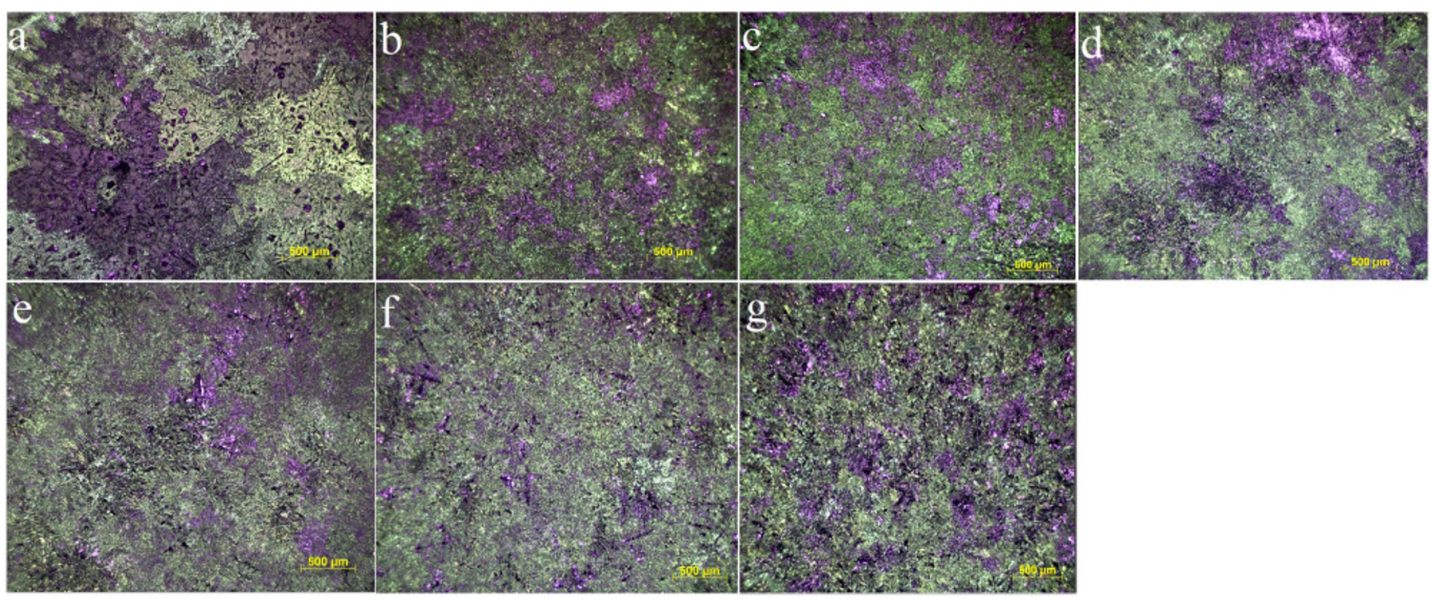

Figure 7. Al12Si1Fe" $X " N b B$ alloy, were: a) $X=0 \%$. b) $X=0.02 \%$. c) $X=0.05 \%$. d) $X=0.1 \%$. e) $X=0.2 \%$. f) $X=0.5 \%$. g) $X=1 \%$.

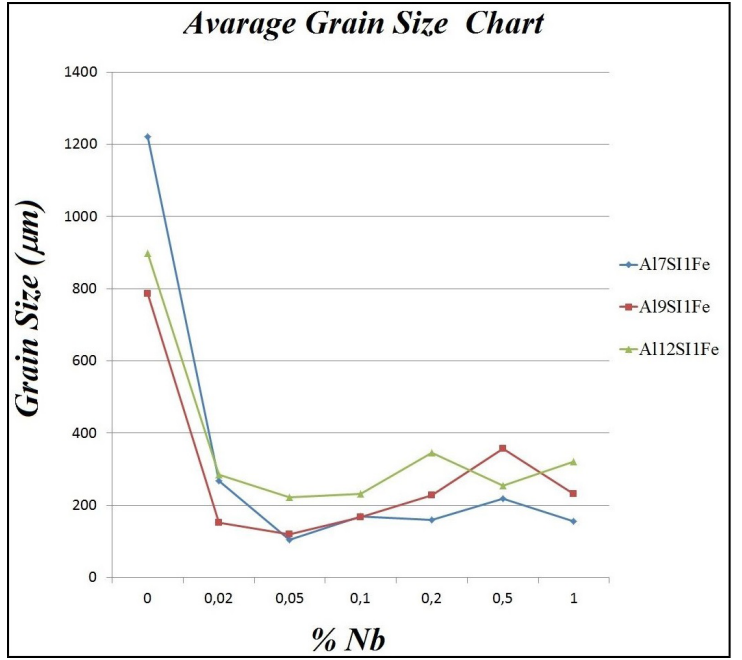

Figure 8. Average Grain Size according to $\mathrm{Nb}$ wt. \%.

According to the graph, regardless of the percentage of the addition of the $\mathrm{NbB}$ inoculant, in general, the reduction in the average grain size was $80 \%$ when compared to the base alloys. The addition of $0.02 \mathrm{Wt} . \%$ of $\mathrm{Nb}$ shows a noticeable improvement in grain size, however, with almost no additional modifications when the $\mathrm{Nb}$ content is increased by more than $0.1 \mathrm{Wt} . \%$, probably due to the temperature used during the melting of the material, which only allowed the maximum solubility of $0.1 \mathrm{Wt} . \% \mathrm{Nb}$ in $\mathrm{Al}$. It was limited the amount of formation of substrates and the appearance of new nuclei. Nb's solubility values in Al are known and available in the literature ${ }^{7}$. The best gain in reducing the average grain size (91\%) was with the addition of $0.05 \mathrm{Wt} \% \mathrm{Nb}$ in the alloy with $7 \mathrm{Wt} . \% \mathrm{Si}$, reaching an average grain of $104 \mu \mathrm{m}$.

The divergences in grain size presented in the studies taken from the literature and the proposed work could easily be attributed to the cooling rate or the percentage of the $\mathrm{Nb}$ inoculant addition in the alloy. However, care was taken to bring examples where the two main parameters were maintained in all samples' production. In this way, the ratio $(\mathrm{Nb} / \mathrm{B})$ and its form of addition will now appear as the reason for the main results. Table 1 showed divergences found in the products, and the consequences of this study are discussed and compared with each other as follows:

Bolzoni et al. ${ }^{16}$ reported that the grain size average was $500 \mu \mathrm{m}$, but the same author Bolzoni et al. ${ }^{10}$ stated that reduced the grain to $250 \mu \mathrm{m}$. However, both studies used the same ratio $(\mathrm{Nb}=\mathrm{B})$ and the same material (LM6), yet with different forms of inoculant additions. 
Bolzoni et al. ${ }^{10}$, in comparison with Bolzoni et al. ${ }^{17}$, found that the average grain size values of $250 \mu \mathrm{m}$ and $220 \mu \mathrm{m}$, were very close, but using a very different ratio $(\mathrm{Nb} / \mathrm{B})$ and materials.

Nowak et al. ${ }^{7}$ used pure Al in his piece of research, and the result was the opposite of all other studies regarding the effects of average grain size according to the ratio $(\mathrm{Nb} / \mathrm{B})$.

Bolzoni et al. ${ }^{10}$, in comparison with Bolzoni and $\mathrm{Babu}^{18}$, used the same ratio $(\mathrm{Nb} / \mathrm{B})$ and the same addition via (master alloy). Still, with different alloys, however, the results show a wildly divergent grain size average of $250 \mu \mathrm{m}$ against $400 \mu \mathrm{m}$, respectively.

Nowak et al. ${ }^{15}$, compared with Bolzoni and $\mathrm{Babu}^{12}$, both use the ratio $(\mathrm{Nb} / \mathrm{B})$, with $\mathrm{Nb}>\mathrm{B}$, added via (master alloy) and with the same material, but the results of average grain size show a difference from $340 \mu \mathrm{m}$ to $250 \mu \mathrm{m}$.

The study proposed in this article differs from the research found in literature mainly due to the ratio $(\mathrm{Nb} / \mathrm{B})$, with $\mathrm{Nb}>>\mathrm{B}$, for the addition of the master alloy $\mathrm{Al}-4 \mathrm{Nb}-0.05 \mathrm{~B}$, via stick, in the alloys Al 7,9,12 Wt.\% of Si $1 \mathrm{Wt} . \%$ of Fe. Considering the addition of $0.1 \mathrm{Wt} . \%$ of $\mathrm{Nb}$, the average grain size results were: for $7 \mathrm{Wt} . \%$ of $\mathrm{Si}=170 \mu \mathrm{m}$; for $9 \mathrm{Wt} . \%$ of $\mathrm{Si}=167 \mu \mathrm{m}$; for $12 \mathrm{Wt} . \%$ of $\mathrm{Si}=232 \mu \mathrm{m}$. Comparing these results with the work by Nowak et al. ${ }^{15}$, using LM6 alloy and ratio $(\mathrm{Nb} / \mathrm{B})=4: 1$, reached an average grain size of $340 \mu \mathrm{m}$, so the results of grain refinement in the proposed study were more significant. Already comparing this proposed study with that by Bolzoni et al. ${ }^{12}$, in which the average grain size was $250 \mu \mathrm{m}$, the grain size results were close.

As shown in general, in Table 1, the results demonstrate that although this is a very recent study line, they are highly dependent on process parameters, which vary significantly from experiment to experiment, a common factor in casting processes.

To go further in this research were analyzed the effects of the master alloy Al-Nb-B on the high Fe content of the alloys Al-Si causing changes in the eutectic morphology intermetallic precipitated phases in the structure of the material. The addition of $\mathrm{Nb}$ somehow altered the precipitation dynamics of the $\beta$-Fe particles, leading to a smaller size of formed particles with the spheroidised morphology. Figures 9 and 10 shows random images of the $\beta$-Fe precipitates found in the alloys without and with $0.05 \mathrm{wt} . \%$ of $\mathrm{Nb}$ addition, respectively.

Figure 11 presents SEM-EDS images showing the alloys' microstructure without $\mathrm{Nb}$ addition (Figures $11 \mathrm{a}, \mathrm{c}, \mathrm{e}$ ) and with $0.02 \mathrm{Nb}-0.0025 \mathrm{~B}$ (Figures $11 \mathrm{~b}, \mathrm{~d}, \mathrm{f}$ ). The Al, Si, and Fe elements are highlighted in blue, green, and red. The $\mathrm{Al}$ element's color has been suppressed in some images for better visualization of the eutectic phase.

Regardless of the Si content, the eutectic microstructural Al-Si alloy showed a certain similarity. In alloys without $\mathrm{Nb}$ addition (Figures $11 \mathrm{a}, \mathrm{c}, \mathrm{e}$ ), the eutectic phase of Al-Si and the intermetallic precipitates $(\beta-\mathrm{Fe})$ are present in the form of needles or coarser platelets. A tiny addition of $0.02 \mathrm{wt}$. $\% \mathrm{Nb}$ was enough to drastically alter the eutectic phase's

\section{Without Nb}

a)

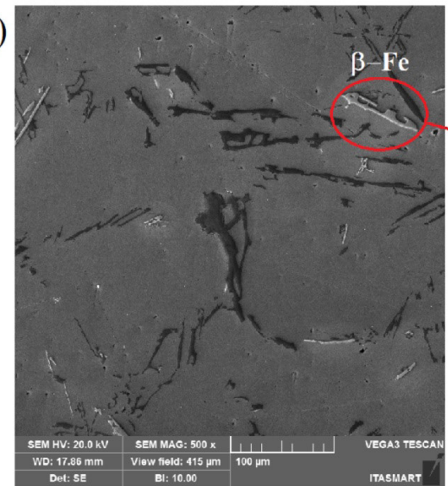

EDS Image

b)

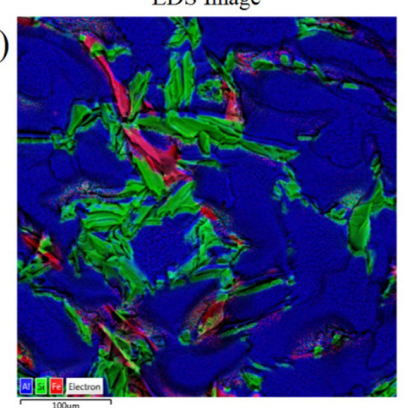

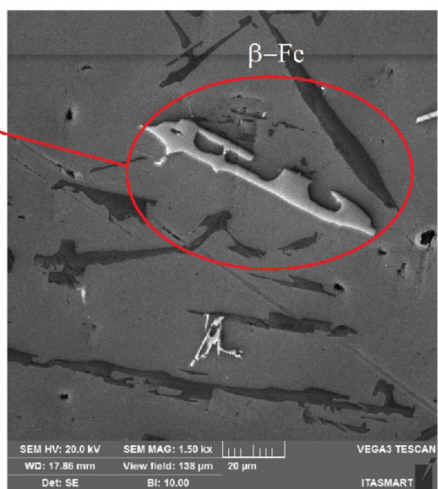

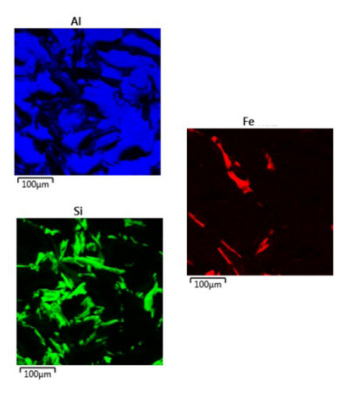

Figure 9. MEV: SEM-EDS maps highlighting typical $\beta$-Fe precipitates present in the alloys containing Al12SilFe without $\mathrm{Nb}+\mathrm{B}$ inoculation. a) $\beta$-Fe highlighting showing image SEM with 500X and 1500X ampliation. b) Al, Si phase, and precipitates of the $\beta$-Fe are highlighted in blue, green, and red. 


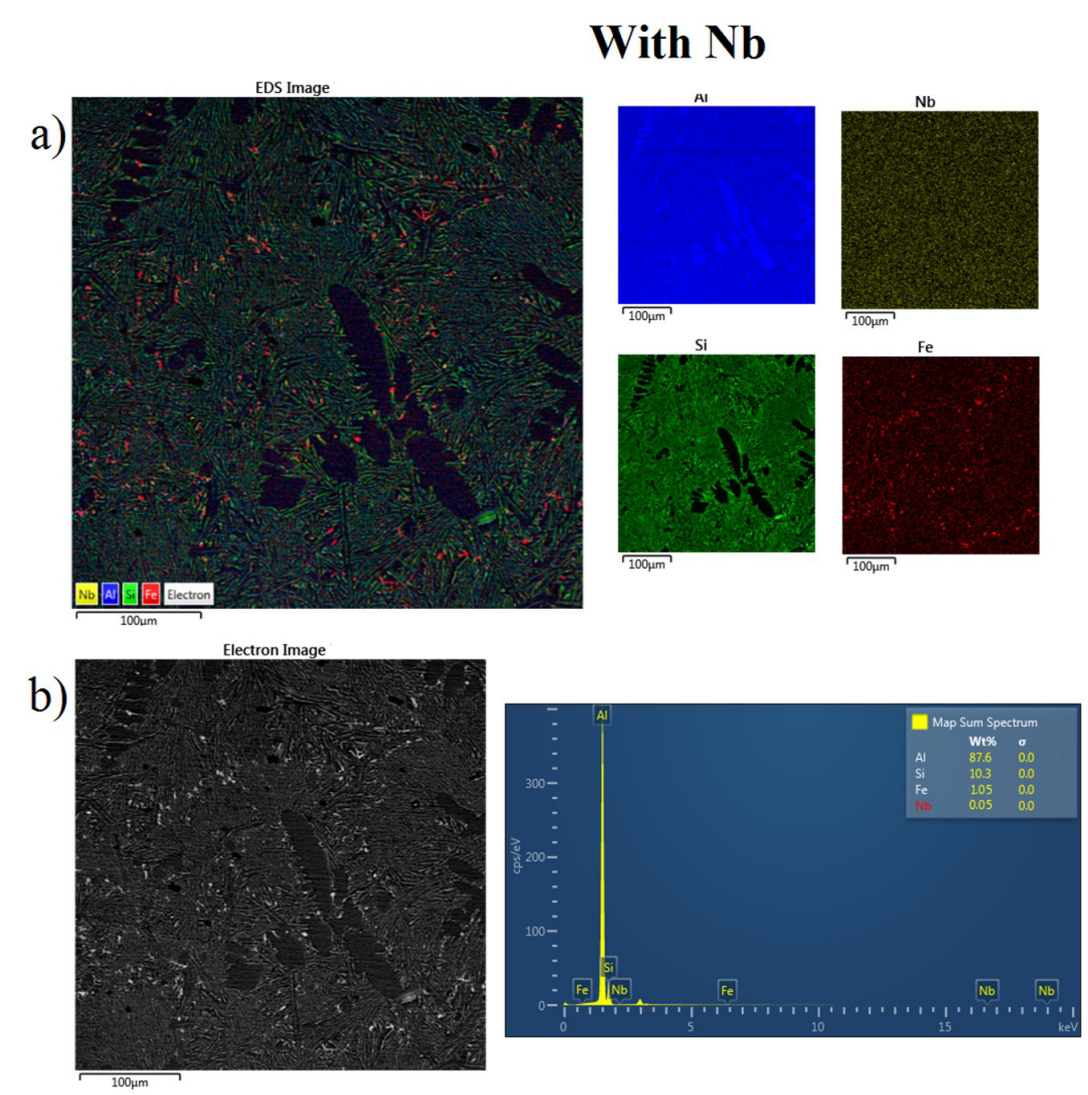

Figure 10. MEV: a) SEM-EDS image shows the microstructure of the alloys containing A112Si1Fe with 0.05 wt. $\%$ of Nb addition. b) Electron image shows $\mathrm{Al}, \mathrm{Si}, \mathrm{Fe}$, and $\mathrm{Nb}$ map sum spectrum.
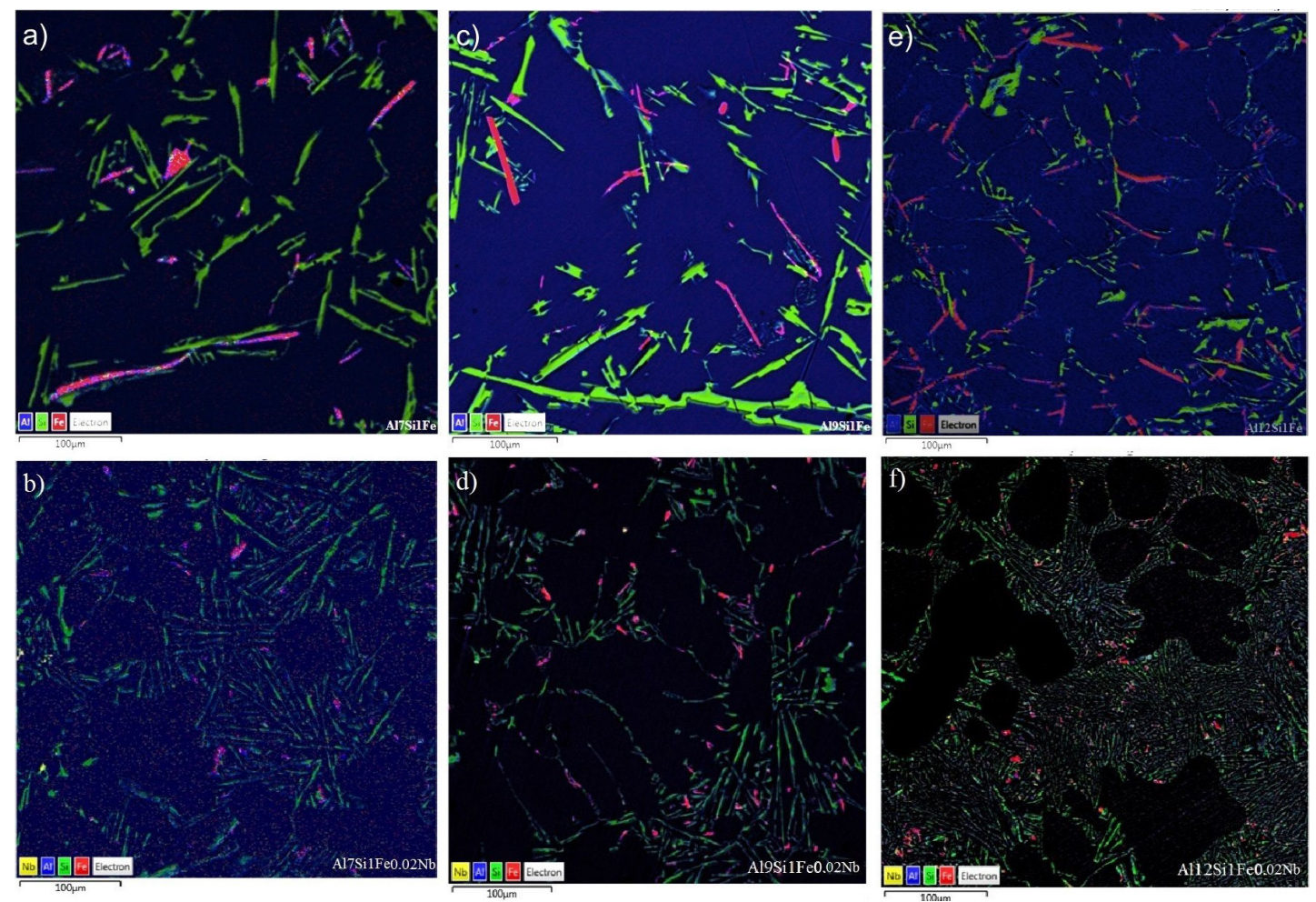

Figure 11. SEM-EDS images showing the microstructure of the alloys containing $7 \mathrm{Wt} . \% \mathrm{Si}$ (a, b), $9 \mathrm{Wt} . \% \mathrm{Si}(\mathrm{c}, \mathrm{d})$ and $12 \mathrm{Wt} . \% \mathrm{Si}$ (e, f); Without $\mathrm{NbB}$ addition (a, c and e) and with $0.02 \mathrm{Wt} . \% \mathrm{Nb}$ and $\mathrm{B}$ according to stoichiometric calculation (b, d, and f). 


\section{Without $\mathrm{Nb}+\mathrm{B}$}

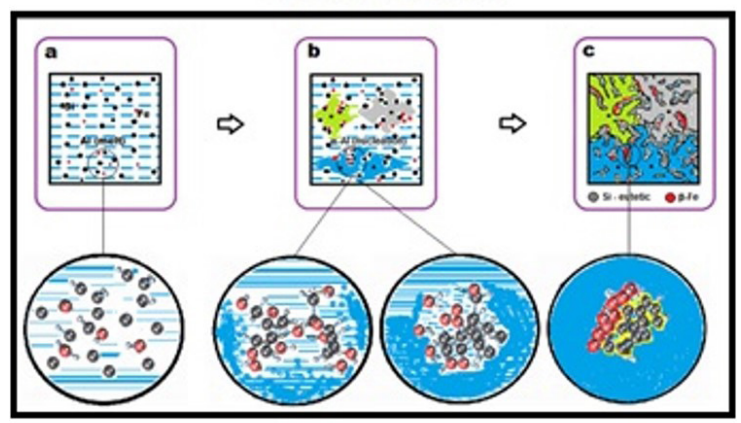

With $\mathrm{Nb}+\mathrm{B}$

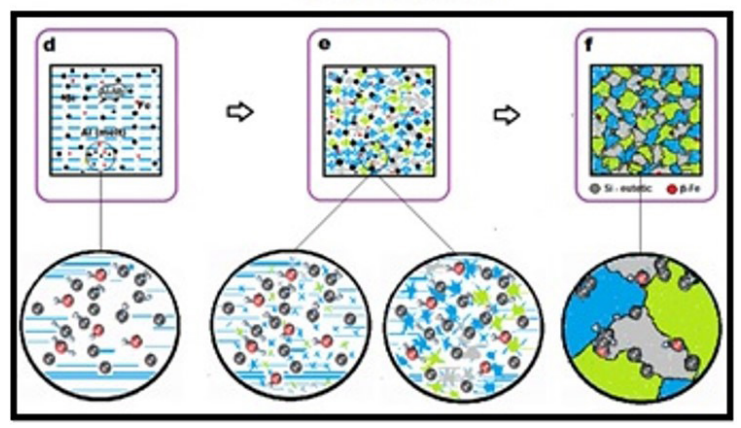

Figure 12. Illustration of the dispersion mechanism of b-Fe particles in the eutectic front of solidification of the material, without the addition of $\mathrm{Nb}+\mathrm{B}(\mathrm{a}, \mathrm{b}, \mathrm{c})$, with the addition of $\mathrm{Nb}+\mathrm{B}(\mathrm{d}, \mathrm{e}, \mathrm{f})$. Liquid metal $(a, d)$. Beginning of the grain's solidification process and growth (b, e). End of solidification (c, f). (Microsoft Paint. Ink 2010).

morphology and size and the $\beta$-Fe precipitates, which became very refined and spheroidized (Figures $11 \mathrm{~b}, \mathrm{~d}, \mathrm{f}$ ).

With the information obtained in the study, it was possible to build a comparative schematic representation suggesting how the phenomenon of transformations in the $\beta$-Fe precipitate morphology occurs without and with the addition of the $\mathrm{Nb}+\mathrm{B}$ inoculant, as shown in Figure 12.

The addition of $\mathrm{Nb}+\mathrm{B}$ caused an exponential increase in the nucleation points through the substrates $\mathrm{Al}_{3} \mathrm{Nb}$ and $\mathrm{NbB}_{2}$ (heterogeneous nucleation), forming a large number of simultaneous grains that ended up restricting the mobility of the solute elements ( $\mathrm{Fe}$ or $\mathrm{Si}$ ) and then, promotes a more homogeneous distribution of the solute elements rejected in the solidification front and eutectic pools, but now trapped among the diverse and reduced dendritic arms of $\alpha$-Al grains, thus avoiding approximations or clusters or interconnectivity between the solute elements and with that the needle-like or coarse platelet shape. Therefore, it can be stated that grain refinement with $\mathrm{Nb}>>\mathrm{B}$ is a strong indicator that the phase characterized by the peritectic reaction with the formation of $\mathrm{Nb}\left(\mathrm{Al}_{3} \mathrm{Nb}\right)$ aluminate particles is an efficient and reliable inoculator for $\alpha$-Al grains. This was also confirmed in the research by Wang et al. ${ }^{22}$ where it demonstrates that $\mathrm{Nb}$ forms not only borides $\left(\mathrm{NbB}_{2}\right)$ but also aluminides $\left(\mathrm{Al}_{3} \mathrm{Nb}\right)$, potential potent substrates of heterogeneous nucleation.

\section{Conclusions}

This study proved the addition of master alloy via $\mathrm{Al}-4 \mathrm{Nb}$ $0.5 \mathrm{~B}$ in alloys with (7 Wt.\%, $9 \mathrm{Wt} . \%$, and $12 \mathrm{Wt} . \%$ ) of $\mathrm{Si}$ and
$1 \mathrm{Wt} . \%$ of Fe was efficient to the refinement of the primary $\alpha-\mathrm{Al}$ grain and the change in the morphology of $\beta$-Fe precipitates.

Minimal addition of $0.02 \mathrm{Wt} . \%$ of $\mathrm{Nb}$ and an amount of $\mathrm{B}$ with $(\mathrm{Nb}>>\mathrm{B})$ was enough to reduce the grain size drastically.

The ratio $(\mathrm{Nb} / \mathrm{B})$ and the form of addition of the inoculant greatly influence grains' refinement.

$\mathrm{Nb}$ aluminates $\left(\mathrm{Al}_{3} \mathrm{Nb}\right)$, formed by the peritectic reaction between $\mathrm{Al}-\mathrm{Nb}$, are efficient and reliable for the refinement of $\alpha-\mathrm{Al}$ grains and subsequent eutectic phases.

With the addition of $\mathrm{NbB}$ elements in Al-Si alloys with critical $\mathrm{Fe}$, there is spraying or spreading of the Fe element among the $\alpha$-Al dendritic grains, inhibiting the formation of $\beta$-Fe coarse morphology in the form of needles or highly facetted platelets, transforming themselves into smaller and more dispersed precipitates in the material structure, with the appearance of the spheroidized type. Then, suggesting an improvement in the mechanical properties of the material.

\section{Acknowledgments}

The authors would like to thank the Brazilian research funding agency CAPES (Federal Agency for the Support and Improvement of Higher Education) - Finance Code 001 for providing financial support for this study. The authors are also indebted to the Aeronautics Institute of Technology (ITA), the Institute for Advanced Studies (IEAv), and the Federal Institute of Education, Science and Technology of São Paulo (IFSP) - Itaquaquecetuba campus, for the practical support very kindly provided.

\section{References}

1. Taylor JA. Iron-containing intermetallic phases in Al-Si based casting Alloys. Procedia Materials Science. 2012;1:19-33.

2. Malavazi J. Caracterização microestrutural dos compostos intermetálicos e seu efeito no comportamento mecânico nas ligas de Al-9\%Si com adições de Fe e Mn [Dissertação]. São Paulo: IPEN; 2013.

3. Mahta M, Emamy M, Cao X, Campbell J. Overview of $\beta$-Al5FeSi phase in Al-Si alloys: materials science research trends. In: Olivante LV. Materials scicence research trends. Chap. 5. New York: Nova Science Publishers, Inc; 2007. p. 1-16.

4. Ebhota WS, Jen T-C. Intermetallic formation and their effect on mechanical properties of Al-Si-X alloys. London: IntechOpen Limited; 2018. http://dx.doi.org/10.5772/ intechopen. 73188 .

5. Basak CB, Babu NH. Morphological changes and segregation of $\beta$-A19Fe2Si2 phase: A perspective from better recyclability of cast Al-Si alloys, BCAST. Mater Des. 2016;108:277-88.

6. Easton M, St John D. An analysis of the relationship between grain size, solute content, and the potency and number density of nucleant particles. Metal Trans A. 2005;36:1911-20.

7. Nowak M, Bolzoni L, Babu NH. Grain refinement of Al-Si alloys by Nb-B inoculation. Part I. Mater Des. 2015;66:366-75.

8. Quadro AL, Raposo MT, Sabariz ALR. Uso do nióbio como refinador de grão para ligas de alumínio-silício. Cadernos UniFOA. 2016;11(10):37-45.

9. Li Y, Jiang Y, Liu B, Luo Q, Hu B, Li Q. Understanding grain refining and anti Si-poisoning effect in Al-10Si/Al-5Nb-B system. J Mater Sci Technol. 2021;65:190-201. 
10. Bolzoni L, Nowak M, Babu NH. Assessment of the influence of $\mathrm{Al}-2 \mathrm{Nb}-2 \mathrm{~B}$ master alloy on the grain refinement and properties of LM6 (A413)alloy. Mater Sci Eng A. 2015;628:230-7.

11. Bolzoni L, Babu NH. Engineering the heterogeneous nuclei in Al-Si alloys for solidification control. Applied Materials Today. 2016;5:255-9.

12. Bolzoni L, Babu NH. Towards industrial Al-Nb-B master alloys for grain refining Al-Si alloys. J Mater Res Technol. 2019;8(6):5631-8.

13. Xu J, Li Y, Hu B, Jian Y, Li Q. Development of Al-Nb-B master alloy with high $\mathrm{Nb} / \mathrm{B}$ ratio for grain refinement of hypoeutectic Al-Si cast alloys. J Mater Sci. 2019;54:1456176.

14. The Aluminum Association. Standard Test Procedure for Aluminum Alloy Grain Refiners - TP1. Virginia: The Aluminum Association; 2012

15. Nowak M, Yeoh WK, Bolzoni L, Babu NH. Development of $\mathrm{Al}-\mathrm{Nb}-\mathrm{B}$ master alloys using $\mathrm{Nb}$ and KBF4 Powders. Mater Des. 2015;75:40-6.

16. Bolzoni L, Nowak M, Babu NH. Grain refinement of Al-Si alloys by $\mathrm{Nb}-\mathrm{B}$ inoculation. Part II: application to commercial alloys. Mater Des. 2015;66:376-83.
17. Bolzoni L, Nowak M, Babu NH. Nb-based heterogeneous nuclei for enhanced $\alpha-\mathrm{Mg}$ nucleation in $\mathrm{Mg}(-\mathrm{Al})$ alloys. Mater Lett. 2016;169:207-9.

18. Bolzoni L, Babu NH. Refinement of the grain size of the LM25 alloy (A356) by96Al-2Nb-2B master alloy. J Mater Process Technol. 2015;222:219-23.

19. ASTM: American Society for Testing and Materials. ASTM E112-10: Standard Test Methods for Determining Average Grain Size. USA: ASTM; 1996.

20. Porter DA, Easterling KE. Phase transformations in metals and alloys by Porter \& Easterling. 2nd ed. London: Chapman \& Hall; 1992.

21. Xu J, Li R, Li Q. Effect of agglomeration on nucleation potency of inoculant particles in the Al-Nb-B master alloy: modeling and experiments. Metall Mater Trans, A Phys Metall Mater Sci. 2021;52:1077-94.

22 Wang F, Qiu D, Taylor J, Easton M, Zhang MX. Crystallographic study of $\mathrm{Al} 3 \mathrm{Zr}$ and $\mathrm{Al} 3 \mathrm{Nb}$ as grain refiners for $\mathrm{Al}$ alloys. Trans Nonferrous Met Soc China. 2014;24(7):2034-40. 